\title{
A relevância do clima organizacional nas organizações
}

\author{
The organizational climate relevance in organizations \\ La relevancia climática organizacional en las organizaciones
}

Recebido: 20/02/2021 | Revisado: 27/02/2021 | Aceito: 21/03/2021 | Publicado: 28/03/2021

\author{
Lorena Ferreira Santos \\ ORCID: https://orcid.org/0000-0003-3522-6854 \\ Grupo Ser Educacional, Brasil \\ E-mail lorena.santos@sereducacional.com \\ Tatiana Torres \\ ORCID: https://orcid.org/0000-0002-2736-9698 \\ Grupo Ser Educacional, Brasil \\ E-mail: tatiana.torres@sereducacional.com \\ Jucimar Casimiro de Andrade \\ ORCID: https://orcid.org/0000-0001-5539-4498 \\ Grupo Ser Educacional, Brasil \\ E-mail: jucimarcandrade@gmail.com \\ Fernando Salvino da Silva \\ ORCID: https://orcid.org/0000-0002-4415-3688 \\ Grupo Ser Educacional, Brasil \\ E-mail: administracao.gestao@sereducacional.com \\ Robson José Silva Santana \\ ORCID: https://orcid.org/0000-0002-2755-9379 \\ Grupo Ser Educacional, Brasil \\ E-mail: prof.robjss@gmail.com \\ Renata Porto Chaves \\ ORCID: https://orcid.org/0000-0002-9800-4776 \\ Grupo Ser Educacional, Brasil \\ E-mail: portorena9@gmail.com \\ Antônielle Patricia Lima da Silva \\ ORCID: https://orcid.org/0000-0003-3652-8547 \\ Grupo Ser Educacional, Brasil \\ E-mail: antoniellelima@gmail.com
}

\section{Resumo}

O presente artigo aborda reflexões acerca do processo organizacional no âmbito empresarial com a finalidade de refletir sobre o bem-estar dos funcionários inseridos no ambiente trabalho. A investigação aqui proposta tem como problemática a forma como o clima organizacionalpode interferir na qualidade de vida dos funcionários. Elaborada com base nos estudos de Chiavenato (2005), Graça (1999), Oliveira (2011), Rizatti (2002) e Russo (2010) que desenvolveram estudos sobre clima organizacional nas organizações, bem-estar dos colaboradores e ambiente de trabalho. Foi adotada como técnica metodológica a pesquisa bibliográfica. Nesse sentido, é possível observar que uma cultura organizacional sólida, com valores estabelecidos, contribui de forma positiva na construção do sujeito perante uma organização.Dessarte, o trabalhador necessita de um planejamento diferenciado pararealizar suas atividades e que possibilitem ao colaborador um melhor desempenho para que alcance o seu principal objetivo na respectiva empresa.

Palavras-chave: Clima organizacional; Empresa; Gestão; Colaborador; Bem-estar.

\begin{abstract}
This article discusses reflections on the organizational process in the business environment in order to reflect on the well-being of employees in the work environment. The research proposed here has as a problem the way the organizational climate can interfere in the quality of life of employees. Prepared based on the studies of Chiavenato (2005), Graça (1999), Oliveira (2011), Rizatti (2002) and Russo (2010) who developed studies on organizational climate in organizations, employee well-being and work environment. Bibliographic research was adopted as a methodological technique. In this sense, it is possible to observe that a solid organizational culture, with established values, contributes positively in the construction of the subject before an organization. Therefore, the worker needs a differentiated planning to carry out his activities and that enable the employee to perform better so that he can reach his main objective in the respective company.
\end{abstract}

Keywords: Organizational climate; Company; Management; Collaborator; Welfare.

\section{Resumen}

Este artículo analiza reflexiones sobre el proceso organizacional en el entorno empresarial conel fin de reflexionar sobre el bienestar de los empleados en el entorno laboral. Nuestra investigación plantea el siguiente problema: ¿cómo puede el clima organizacional interferir conla calidad de vida de los empleados? el cual fue elaborado a partir de los estudios de Chiavenato(2005), Graça (1999), Oliveira (2011), Rizatti (2002) y Russo (2010) quienes presentan un estudio sobre clima organizacional en las organizaciones; el bienestar de los empleados y el entorno laboral. Adoptamos la investigación bibliográfica como técnicas metodológicas. Así, notamos que el proceso de una práctica más significativa 
en el clima organizacional actúa de manera más efectiva, si existe una cultura organizacional sólida, con sus debidos valores, ya que contribuye positivamente en la construcción del sujeto ante una organización. Así, el trabajador necesita una planificación diferente para el desarrollo de sus actividades que le permitan desempeñarse mejor para que pueda alcanzar su objetivo principal en la respectiva empresa que se inserta.

Palavras clave: Clima organizacional; Empresa; Administración; Colaborador; Bienestar.

\section{Introdução}

Bispo (2006) afirma que o relacionamento entre as empresas e seus clientes sempre foi focode muito estudo. Entretanto, a relação entre as empresas e seus colaboradores não recebia a mesma atenção. Contudo, ao longo dos anos este cenário parece estar mudando. Pesquisas de qualidade de vida no trabalho, ergonomia, gestão de pessoas, saúde mental no trabalho e o combate ao assédio moral no trabalho mostram que as empresas estão preocupadas com os funcionários, pois são engrenagens importantíssimas das organizações e que por muito tempo foram negligenciados.

Partindo dessa premissa, observamos que o clima organizacional se modifica de acordo com a empresa, cultura e colaboradores, pois a equipe de trabalho deve manter um foco de engajamento para melhor desempenhar suas respectivas tarefas no ambiente de trabalho. Destaforma, medidas estabelecidas pela empresa e seus colaboradores, acarretam em impactos positivos e negativos, a depender de como cada papel está sendo exercido na sua respectiva função.

Segundo Santos (2001), os resultados das organizações dependem de três variáveis: pessoas, processos e filosofia estratégica. As pessoas, na busca dos resultados, utilizamprocessos que são orientados pela filosofia estratégica da empresa. Quanto maior for a interação entre três variáveis, maior a sinergia do modelo. Logo, a busca dos resultados está relacionada à forma como os colaboradores trabalham, os processos utilizados nesse trabalho, colocando em prática a estratégia da organização.

Esse trabalho busca analisar a importância do clima organizacional no âmbito empresarial.Através do levantamento bibliográfico evidenciou-se a problemática de que muitoscolaboradores de empresas privadas, na maioria das vezes, não vivenciam um bem-estar em seuambiente de trabalho. O estudo aqui apresentado tem como objetivo geral analisar como está sendo desenvolvida a qualidade de vida dos colaboradores dentro das empresas.

O trabalho está estruturado em torno do seguinte problema: De que forma o clima organizacional pode interferir na qualidade de vida dos funcionários? Considerando o problemade pesquisa mencionado, tem-se como objeto de investigação a análise das práticas organizacionais dos gestores e equipe de colaboradores em empresa privada.

O problema de pesquisa citado anteriormente justifica-se pela necessidade de analisar como as dificuldades e o clima organizacional influenciam na eficácia dos funcionários durantea sua rotina de trabalho na empresa, utilizando um arcabouço teórico como suporte investigativopara interagir com nossa proposta.

Sendo assim, pretende-se compreender como se dá o processo relacional no âmbitoempresarial. Mediante a proposição sobre o clima organizacional nas empresas, houve uma inquietação para analisar se os colaboradores estão em um ambiente significativo no âmbito profissional. Sabemos que em algumas empresas a rotina de trabalho é intensa e ultrapassa as horas contratuais, não proporcionando uma carga horária adequada aos seus funcionários, comisso, surgem colaboradores insatisfeitos com sua função. Assim, analisaremos quais são as principais dificuldades que esses colaboradores vivenciam em sua rotina de trabalho e suas implicações.

A pesquisa terá como aporte teórico Chiavenato (2005), Graça (1999), Oliveira (2011), Rizatti (2002) e Russo (2010), ambos defendendo a prática do clima organizacional nas empresas que pressupõe uma reflexão pautada no bem-estar dos colaboradores.

Os procedimentos metodológicos que adotamos para o nosso trabalho, foram baseados através de uma abordagem bibliográfica, selecionando publicações impressas, tais como: livros, monografias, artigos, documentos oficiais, além de referencial teórico divulgado em meio eletrônico, como artigos e monografias. 


\section{Fundamentação Teórica}

\subsection{A importância do Clima Organizacional}

O clima organizacional se consolidou como uma temática relevante no ambiente de trabalhodos colaboradores. Este interfere na qualidade de vida dos funcionários, pois em decorrência destepodem surgir situações de saúde que afetam diretamente a vida desses colaboradores.

Para Chiavenato (2005), o termo clima organizacional se refere aos aspectos internos de uma organização, à atmosfera psicológica e às características da empresa, ele pode ser sentido psicologicamente e está relacionado especificamente às propriedades motivacionais do ambiente interno da organização. O clima compõe a qualidade do ambiente da empresa, sendo percebido pelos colaboradores da organização e influenciando diretamente o comportamento dosmesmos. O autor ainda ressalta a influência do clima na motivação:

O clima organizacional influencia a motivação, o desempenho humano e a satisfação notrabalho. Ele cria certos tipos de expectativas sobre as quais consequências se seguemem decorrência de diferentes ações. As pessoas esperam certas recompensas, satisfaçõese frustrações na base de suas percepções do clima organizacional. Essas expectativas -quando positivas - tendem a aumentar a motivação das pessoas (Chiavenato, 2005,p. 45).

Souza (2004) assevera que "o clima é uma resultante das variáveis culturais, assim entendidas como a soma dos valores, costumes, tradições, e propósitos que fazem com que uma empresa seja singular”. O autor acredita que, quando essas variáveis são modificadas, ocasionam alterações no clima, e isso é mais perceptível do que suas fontes causais. Relacionando esse pensamento, Litwin e Stringer (apud Graças, 1999, p. 10) identificaram sete variáveis-chave no clima organizacional, as quais definiram como suas dimensões: conformismo com a estrutura da empresa; responsabilidade pessoal; padrões de desempenho; recompensas; clareza organizacional; liderança; apoio e calor humano.

Sendo assim, é função da empresa, propiciar aos seus funcionários uma qualidade de funçãomais significativa. Tendo em vista esse papel, Graças (1999, p. 23) diz o seguinte acerca do papel do Recursos Humanos da empresa:

A Administração de Recursos Humanos ou do Ativo Humano, como querem alguns, busca, entre outros objetivos, alcançar a satisfação e a "motivação" dos colaboradoresda organização. Ela deve procurar o pleno aproveitamento desses recursos, dispondo-os para que ofereçam um maior rendimento organizacional, expresso em termos de efetividade e produtividade, com o melhor nível de realização individual, expresso emtermos de satisfação pessoal e geral. Para isso, ela precisa diagnosticar, periodicamente o clima organizacional, com o objetivo de saber se a parte mais nobrede sua missão está sendo atingida.

Quando o administrador compreende o conceito de clima organizacional, pode manejar a motivação de seus colaboradores, aumentando a eficiência de sua equipe de colaboradores. A motivação pode ser definida como o processo responsável pelaintensidade, direção e persistência dos esforços de uma pessoa para o alcance de uma determinada meta (Robbins, 2002).

Segundo Chiavenato (2005, p. 215), "a motivação existe dentro das pessoas e se dinamizacom as necessidades humanas". Chiavenato acredita que a motivação é uma função gerencial:

Na realidade, a motivação está contida dentro das próprias pessoas e pode ser amplamente influenciada por fontes externas ao indivíduo ou pelo seu próprio trabalho na empresa. A motivação intrínseca e extrínseca deve se complementar por meio do trabalho gerencial. Ambas não podem ser deixadas ao acaso, simplesmente àmercê dos acontecimentos. Elas podem e devem ser perfeitamente compreendidas pelo gerente e utilizadas como ponto de apoio para potencializar e alavancar a satisfação das pessoas. O gerente deve conhecer o potencial interno de motivação de cada pessoa e deve saber extrair do ambiente de trabalho as condições externas para elevar a satisfação profissional (Chiavenato, 2005, p. 215).

Moreira (2012) compreende a cultura organizacional como as práticas adotadas pela organização, isto é, os princípios, as condutas, os procedimentos, as ideologias, a missão e a visão da corporação. Define as características fundamentais da corporação. É a começar dela que se impõe disciplina na empresa, é nela que os funcionários irão se orientar para elaborar 
seus preceitos e funcionamento e é por meio da cultura, também, que se forma um ambiente detrabalho saudável.

Russo (2010) explica que a cultura organizacional pode ser definida como o modelo dos valores e crenças compartilhados pelos colaboradores, que auxilia o indivíduo a entender oandamento organizacional e oferecem diretrizes e sentido para o comportamento nas organizações. Representa a estrutura mais profunda das organizações, fixado pelos valores compartilhados pelos seus colaboradores. É indispensável que os líderes da empresa sejam capazes de identifica-la.

Matos e Almeida (2007) destacam que a cultura organizacional é definida, também, como um agrupamento de fenômenos decorrentes da ação humana, concebida dentro das fronteiras de um sistema. A cultura organizacional é estruturada em três elementos: os preceitos, a tecnologia e o caráter. Cada empresa tem sua cultura, seus valores, regras e convicções que repercutem nas suas estratégias e no seu posicionamento competitivo. No cotidiano, as pessoaspercebem que é necessário cumprir as regras e normas estabelecidas pela cultura para não falhar.

Russo (2010) compreende que a cultura realiza influência significativa na conduta, na missão e nas metas organizacionais que devem estar alinhadas a ela. Assim, a cultura organizacional leva a empresa para uma direção, correta ou não. Nessa perspectiva, a cultura éfundamental em razão de dar consistência à organização e aos seus colaboradores, concede ordem e estrutura para o andamento das atividades e determina o modo de como as pessoas serelacionam, entre elas e com a organização.

Mayo (2003) compreende que a cultura não permite ser modificada facilmente. Todas as influências do ambiente que existem na cultura se integram no clima, abrangendo os seguintes aspectos: conduta de comportamento; uma quantidade de divertimento combinada com o trabalho; a compensação; o nível de liberdade diante do controle; a combinação entre poder e compromisso; a capacidade e êxito da comunicação; tamanho da confiança na organização; o grau de atenção e flexibilidade com as pessoas.

Porém, para Rosso (2004), há confusão entre os dois conceitos se analisadas com poucaatenção. Pois em cultura consideram-se os valores, as práticas, as normas, os símbolos, oshábitos, as crenças, as atitudes comuns dos indivíduos, as cerimonias e as políticas, porémquando tratamos sobre clima organizacional estamos salientando as sensações e os sentimentosinternos que elevam ou reduzem o nível de satisfação dos colaboradores dentro da organização.

Segundo Ferreira, Fortuna e Tachizawa (2006) o Clima Organizacional é a qualidade ou propriedade do ambiente da empresa. Ela é percebida ou experimentada pelos colaboradoresda empresa e influencia seu comportamento.

Este é o ambiente interno, onde os membros da organização convivem entre si e, por este motivo há uma ligação com o grau de motivação e satisfação deles [...] quando o Clima Organizacional é favorável concede a possibilidade de satisfazer as necessidades desses membros, porém quando é desfavorável essas necessidades não são satisfeitas (Ferreira, Fortuna \& Tachizawa, 2006).

Segundo Rizatti (2002, p. 27), clima organizacional está relacionado "com abstrações significativas de conjuntos de indícios baseados nos acontecimentos, condições, práticas e procedimentos que ocorrem e caracterizam a vida diária de uma organização", ou seja, está diretamente relacionado com os "conceitos que os indivíduos partilham a respeito do lugar emque trabalham".

\subsection{Benefícios em desenvolver um clima organizacional interno}

Assegurar uma empresa em pleno funcionamento e com índices elevados/eficazes de produtividade, garante uma manutenção de faturamento e um excelente clima corporativo. Desse modo, um ambiente positivo é capaz de incentivar os colaboradores envolvidos a dar o melhor de si, sendo eles, proativos e executores de suas tarefas, realizando-as com dedicação e significância. Robbins (2010) tem por conceito de satisfação no ambiente profissional a atitudegeral de uma pessoa em relação ao desenvolvimento de suas funções, envolvendo as relações de profissionais, até mesmo as relações de poder; o ambiente; a organização do trabalho; as políticas e programas de gestão da empresa; suas tecnologias; metas, objetivos e interesses; seu ambiente econômico-financeiro; sua história e os desejos dos colaboradores no sentido singulare coletivo.

Sujeitos que apresentam uma qualidade de vida laboral de forma eficaz fortalecem um clima positivo dentro da empresa que estão inseridos, uma vez que criam bons hábitos entre osdemais colegas e, principalmente a disseminação de boas notícias, 
além de expor suas concepções acerca de temáticas apresentadas.

Busch, Fallan e Pettersen (1998) entendem por satisfação no trabalho por um conceito unidimensional de satisfação no trabalho ou um constructo multidimensional, facetado, queprende distintos aspectos de uma situação de trabalho, podendo variar de forma independente emensurado separadamente. Desse modo, o clima organizacional é um processo positivo para aprodução na empresa, sendo eles: um bom engajamento, criatividade, motivação e retenção. Além disso, reduz conflitos internos e retrabalhos entre os colaboradores.

Para Fraser (1983) a satisfação no trabalho é considerada um fenômeno complexo e dedifícil definição, tendo como parte dessa dificuldade seu estado subjetivo em que a satisfação com uma situação pode alterar de indivíduo para indivíduo, de circunstância para circunstância e de tempo em tempo para a mesma pessoa. Estando sujeita as influências de forças internas e externa do ambiente de trabalho imediato.

Um bom desempenho interno produz profissionais mais criativos, com mais produtividade, atuando de forma motivacional e sendo engajadores dos seus próprios objetivos.Reduzindo conflitos internos, elaborando funções mais eficientes e melhorias na comunicação.Sendo assim, colaboradores que atuam desta forma, mantém um ambiente mais saudável e comum bom relacionamento interpessoal com ganhos altos e uma sanidade mental positiva.

\subsection{A relevância do clima organizacional e suas implicações}

Segundo Chiavenato (2010) as pessoas permanecem em seu local de trabalho durante amaior parte do tempo e, portanto, formam ali seu habitar. "A satisfação seria uma causaprovável de um desempenho melhor, mas este não seria uma causa de maior satisfação notrabalho" (Judge; Robbins \& Sobral, 2010, p.77). Clima organizacional é o nome dadopara o produto dos sentimentos. Os sentimentos e as percepções que estão ligadas a realidadeobjetiva da organização são: satisfação, insatisfação e indiferença, sendo que esses sentimentose percepções são afetados por todos os componentes, desde o local físico até os objetivos. Tudoinfluencia na maneira como as pessoas se sentem em relação à empresa. (Maximiano, 2010).

De acordo com Judge; Robbins e Sobral (2010) quando passamos do nível individual para o nível organizacional, igualmente localizamos a correlação de satisfação-desempenho. Assimcomo as organizações recebem dados como um todo de satisfação e produtividade, observa-seque aquelas que possuem um número menor de funcionários satisfeitos tendem a ser menos eficazes que aquelas com um número maior de funcionários satisfeitos.

Colaboradores satisfeitos tendem a falar bem da empresa, a contribuir com os colegas e a excederem as expectativas com relação ao trabalho, podendo também superar suas atribuiçõesregulares pelo anseio de retribuir as expectativas positivas (Judge; Robbins \& Sobral, 2010).

Tagliocolo e Araújo (2007) explicam as características de cada dimensão encontrada no ambiente de trabalho por meio do clima organizacional: Resistência à mudança: está relacionado com as alterações das rotinas de trabalho por outra mais eficiente e envolve a participação dos funcionários neste processo de implantação e adequação a um novo sistema.

Um clima ruim pode gerar uma carga de estresse e influenciar de forma positiva ou negativana motivação dos colaboradores.

$\mathrm{O}$ estresse está relacionado às ações rotineiras, o que envolve o relacionamento com as demais pessoas. Este, afeta a produtividade dos funcionários e pode ser causado tanto por fatores pessoais quanto organizacionais. Já a motivação está mais ligada a aspectos internos do que externos. O estímulo interno parte da organização faz com que os funcionários sintam-se motivados a passem a ter uma maior produtividade.

A liderança relaciona líder e colaborador, bons líderes influenciam e motivam seus colaboradores, sua equipe de trabalho, e assim a organização se torna mais eficiente e eficaz. Bons líderes geram mais resultados positivos.

\section{Metodologia}

Para compor a metodologia do presente trabalho, optamos por um processo técnico bibliográfico. Segundo Gil (2010), é desenvolvido a partir de material já elaborado, constituídoprincipalmente de livros e artigos científicos. Pesquisa bibliográfica é 
toda bibliografia tornadapública, tais como: jornais, revistas, livros, ou até mesmo gravações em fita magnética(Marconi; Lakatos, 2007, p.57). Desse modo, buscamos mostrar por meio de dados bibliográficos do qual é necessário o entendimento acerca do clima organizacional inseridos naempresa. Aderindo ao que afirma Gil, Michaliszyn e Tomasini (2008, p.51), expõem que a pesquisa bibliográfica e documental é "desenvolvida a partir de referências teóricas queapareçam em livros, artigos, documentos, etc.”. Junior (2009, p.49) adiciona ainda as fontes eletrônicas às definições anteriormente apresentadas, ao asseverar que a pesquisa bibliográfica“é o tipo de pesquisa na qual o pesquisador busca em fontes impressas ou eletrônicas (CD e ou internet), ou na literatura cinza, as informações que necessita para desenvolver uma determinada teoria".

A pesquisa bibliográfica é então feita com o intuito de levantar um conhecimento disponível sobre teorias, a fim de analisar, produzir ou explicar um objeto sendo investigado. A pesquisa bibliográfica visa então analisar as principais teorias de um tema, e pode ser realizada com diferentes finalidades. (Chiara; Kaimen, et al., 2008).

Posteriormente, será realizado um confronto de alguns teóricos que abordem sobre essatemática, considerando as suas implicações para a prática do clima organizacional,especificamente, no bem-estar dos colaboradores. Acreditamos que com isso, muitas questõesque ficaram vagas a respeito do tema proposto, será desvendada e é bastante relevante. Assima pesquisa pode ser caraterizada pela busca de dados sobre os problemas que se deseja conhecer.

Conforme já exposto aqui, a prática de estimular um bom desempenho organizacional tem uma importância muito grande dentro e fora do núcleo empresarial. Além de englobar diferentes saberes, socializa com aspecto culturais, interagindo diretamente com o colaborador,quebrando aquele gelo inicial de que o processo do clima organizacional é complexo, especialmente. $\mathrm{O}$ estudo coleta e analisa as informações em determinados grupos a fim de estudar certos aspectos de sua vida, de acordo com interesse da pesquisa.

Os colaboradores e empresários precisam abraçar essa prática trazendo uma visão que permita aceitar as mudanças compostas pela diversidade em torno de todos da equipe. Não se preocupando com uma camada social que quer deixar escapar a essência de expandir uma prática diferenciada, que carrega enquanto identidade representativa de um povo, o trabalho árduo, mas satisfatório desses colaboradores.

\section{Resultados e Discussão}

Nesta parte, apresentamos concepções especulativas acerca do processo do clima organizacional nas organizações, além da reflexão acerca das práticas realizadas; de acordo com perspectivas de diferentes teóricos que estudam tais temáticas.

De acordo com Luz (1996), o clima organizacional é considerado um conjunto de valores e atitudes de padrões de comportamentos existentes em uma organização, que reflete ograu de satisfação das pessoas no trabalho. É o reflexo do estado de espírito ou de ânimo das pessoas em um determinado período.

Segundo Chiavenato (2004, p. 119) o clima organizacional é a qualidade ou propriedadedo ambiente organizacional que é percebida ou experimentada pelos participantes da organização e influencia o seu comportamento.

Para Bergamini (1997, p. 98), Clima Organizacional nada mais é do que indicador do nível de satisfação (ou insatisfação) experimentado pelos empregados no trabalho.

De acordo com Chiavenato (2010), a essência da cultura de uma empresa é expressa pela maneira como ela faz seus negócios, trata seus clientes e funcionários, pelo grau de autonomia ou liberdade que existe em suas unidades ou escritórios e pelo grau de lealdade expresso por seus funcionários a respeito da empresa. A cultura organizacional representa as percepções dos dirigentes e colaboradores da organização e reflete a mentalidade que predomina na organização. Mais do que isso, a cultura organizacional é uma forma deinterpretação da realidade organizacional e constitui uma modelagem para lidar com questões organizacionais.

De acordo com Lima e Albano (2002, p.3), o clima surge procedente dos valores e tradições que cada um dos envolvidos no processo trouxer para dentro da organização,influenciando, desta maneira, no estilo gerencial ou de liderança.

A questão do clima organizacional na implementação do planejamento estratégico não é responsabilidade de um só indivíduo ou de um único departamento, mas, sim, de todos, e deveorientar a maneira de pensar e agir de toda a instituição. Desta 
forma, todos devem participar dela, desenvolver esforços na direção dos objetivos institucionais, na busca da melhoria do ambiente institucional (Lucena, 2004).

Um dos aspectos que influência na implementação do planejamento estratégico é a análise do clima organizacional nas universidades, aonde teremos uma visão sobre a participação da comunidade universitária na definição da sua política, dos objetivos e das estratégias institucionais e administrativas. Quando esta participação é reduzida, constata-se uma queda na qualidade do desempenho institucional. Por isso é importante que todos se envolvam na definição das políticas e estratégias voltados para melhoria continua da instituição.A participação, quando não adequada, tende a provocar momentos de incerteza e instabilidadena condução dos processos da instituição e, por conseguinte, incessante questionamento sobre as diretrizes, qualidade e políticas universitárias (Lucena, 2004).

A participação não é algo que possa se impor às pessoas, nem pela alta administração, nem pela legislação. É um processo que depende do interesse, da vontade e do conhecimento dos indivíduos envolvidos. O processo participativo é uma das formas para buscar a qualidadepermanentemente entre os diversos segmentos da comunidade universitária. Toda organização possui um sistema de decisões, no qual seus colaboradores participam, escolhendo e decidindodentre as alternativas mais ou menos racionais com que se defrontam. Quando existe participação e envolvimento de forma ativa consequentemente a implementação doplanejamento estratégico ocorrerá de maneira mais harmoniosa, assim fica evidente a importância da análise do clima organizacional para saber como está o nível de participação noambiente de trabalho (Luz, 2001).

Na concepção de Vendramini (2000) o estudo do clima organizacional para a implementação do Planejamento Estratégico é importante por referir-se especificamente às propriedades técnicas administrativas e motivacionais do ambiente organizacional, ou seja, àqueles aspectos do clima organizacional que levam ao sucesso das instituições universitárias.Portanto, o clima representa uma soma das expectativas geradas em uma situação, e é um fenômeno grupal, resultante e característico de uma coletividade. É um conceito que engloba tanto os fatos humanos e materiais como os abstratos, resultantes do convívio humano institucional e isso tudo contribui ou facilita na implementação do planejamento estratégico.

Conforme Luz (2000) O clima retrata o grau de satisfação material e emocional das pessoas no trabalho. Observa-se que este clima influencia profundamente a produtividade do indivíduo e, consequentemente da empresa. Assim sendo, o mesmo deve ser favorável e proporcionar motivação e interesse nos colaboradores, além de uma boa relação entre os funcionários e a empresa.

O clima organizacional é de suma importância na implementação no planejamento estratégico para alcance dos resultados pretendidos pela organização, pois integra a sinergia naequipe e desta forma os resultados surgem de maneira natural, causando aumento da autoestimadas pessoas e sucesso organizacional (Lucena, 2004).

Verificamos a partir desta discussão que o clima organizacional a partir de uma prática maissignificativa, ajuda o colaborador a dominar melhor o seu desempenho e auxilia na construçãode conhecimento durante o processo laboral. Desse modo, enquanto método tem muito a contribuir para que haja uma harmonia no âmbito empresarial, uma vez que a empresa proporcionará aos funcionários uma melhor qualidade de vida.

\section{Considerações Finais}

No decorrer do projeto, foi abordado a discussão sobre a prática de atividades que envolvam um melhor desempenho a partir de atividades que corroborem a finalidade de proporum clima organizacional nas empresas. Tendo como objetivo a investigação da prática das atividades realizadas pelos colaboradores e empregadores nas empresas.

Dessa forma, o estudo propicia uma reflexão acerca do que aborda o clima organizacional e o que corrobora acerca de devidas decisões significativas para uma melhor harmonia no ambiente laboral. Pois, adotar essas medidas garante uma organização que traz diversas contribuições aos colaboradores, uma vez que quando é possível identificar os problemas mais explícitos ou não, facilita a implantação de planejamentos que visa a melhoraras mudanças necessárias na garantia de uma eficaz satisfação de vários colaboradores.

Neste sentindo, faz-se necessário organizar peças indispensáveis na implantação de umplanejamento positivo, pois é 
uma forma de garantir e diagnosticar o âmbito organizacional, visando beneficiar todo envolvimento estabelecido, executando comprometimento e participação direta nas atividades durante a execução de todo planejamento.

Portanto, esse trabalho teve a finalidade de refletir acerca do clima organizacional no âmbito empresarial, visando o bem-estar e qualidade de vida dos funcionários. Desta forma, torna-se emergente uma prática que corrobore com estratégias nas empresas para que haja mudança nesse quadro tão insatisfatório para a formação de um sujeito-colaborador participativo na vida social.

O clima organizacional é de grande relevância para a vida do sujeito agente transformador, desta forma, compete ao empregador-colaborador utilizar estratégias e fazer usodela de forma significativa, garantindo um resultado positivo ao crescimento de funcionárioscríticos e capacitados em seu contexto social.

Recomenda-se que sejam realizados estudos futuros tendo como base a análise do clima organizacional em outras instituições públicas e privadas como forma de melhor compreender como a mesma interfere nos resultados e na dinâmica organizacional.

\section{Referências}

Bispo, C. A. F. (2008). Um novo modelo de pesquisa de clima organizacional. Revista Produção, 18(2).

Bergamini, C. W. (1997). Motivação nas organizações. (4a. ed.), Atlas.

Chiavenato, I. (2004). Introdução à Teoria Geral da Administração. (3a ed.), Elsevier.

Chiavenato, I. (2005). Gerenciando com as pessoas: transformando o executivo em um excelente gestor de pessoas: um guia para o executivo aprender a lidar com sua equipe de trabalho. Elsevier.

Chiavenato, I. (2010). Gestão de Pessoas: o novo papel dos recursos humanos nas organizações. (3a ed.), Elsevier.

Ferreira, V. C. P., Fortuna, A. A. M., \& Tachizawa, T. (2006). Gestão com Pessoas: uma abordagem aplicada às estratégias de negócios. (5a. ed.), Editora FGV.

Guerreiro, R. (1991). Mensuração do resultado econômico. Caderno de EstudosFipecafi.

Graça, H.. (1999). Clima organizacional: uma abordagem vivencial. Funadesp.

Lima, S. M. B., \& Albano, A. G. (2002). Um estudo sobre Clima e Cultura Organizacional na concepção de diferentes autores. Revista CCEI/URCAMP, 6 (10).

Lucena, M. D. da S. (2004). Planejamento estratégico e gestão do desempenho para resultados. Atlas.

Luz, R. S. (1996). Clima Organizacional. Qualitymark.

Luz, J. P. da. (2001). Metodologia para análise de clima organizacional: um estudo de caso para o Banco do Estado de Santa Catarina. Dissertação (Mestrado no Programa de Pós- Graduação em Engenharia de Produção) - Universidade Federal de Santa Catarina. UFSC.

Matos, J. G. R., Matos, R. M. B., \& Almeida, J. R. de. (2007). Análise do ambiente corporativo: E-Papers.

Marconi, M. de A., \& Lakatos, E. M.. (2007). Metodologia cientifica: ciência e conhecimento científico, métodos científicos, teoria, hipóteses e variáveis. (5 ed.) Atlas.

Moreira, E. G. (2012). Clima organizacional. Iesde.

Maximinao, A. C. A. (2010). Introdução à Administração. (7a. ed.) Atlas.

Oliveira, M. M. de . (2011). Como fazer projetos, relatórios monografias, dissertações eteses. (5a. ed.) Elsevier, 2011.

Rizatti, G. (2002). Categorias de análise de clima organizacional em universidades federais brasileiras. Tese (doutorado) - Universidade Federal de Santa Catarina, Centro Tecnológico. Programa de Pós-Graduação em Engenharia de Produção.

Robbins, S. P. (2002). Comportamento organizacional.(9. ed.) Prentice Hall.

Robbins, S. P., Judge, T. A. \& Sobrasl, F. (2010). Comportamento Organizacional. (14a. ed.), Pearson Prentice Hall.

Russo, G. M. (2010). Diagnóstico da cultura organizacional. Elsevier.

Santos, J. L., Kelm, M. L., \& Abreu, A. F. (2001). Um modelo de gestão por resultados segundo ateoria da agência - um estudo de caso: Banco do Estado de Santa Catarina S/A. Revista de Administração da USP, 36 (3).

Tagliocolo, C., \& Aaraújo, G. C. (2007). Clima Organizacional: um estudo sobre as quatro dimensões de análise. Faculdades Integradas Rui Barbosa: Seget. 